\title{
Resenha de livro: Tecnologia Lítica na Arqueologia Brasileira. Coletânea de (re)publicações
}

\author{
Juliana de Resende Machado ${ }^{1,2}$
}

1. Université Paris Nanterre - Laboratoire de Préhistoire et Technologie. 21 allée de l’Université. 92023. Nanterre. França.

2. Musée du Quai Branly - Département de la recherche et de l’enseignement. 222 rue de l’Université. 75007, Paris, França. E-mail: juliana.machado@mae.u-paris10.fr

Tecnologia lítica na arqueologia brasileira. Coletânea de (re)publicações

Organizado por Luydy Fernandes e Déborah Duarte-Talim

Museu de História Natural e Jardim Botânico, Universidade Federal de Minas Gerais, 2017, pp. 237. ISBN 978-85-62164-11-8

O livro em questão consiste numa coletânea de (re)publicações que alguns dos pesquisadores e colaboradores do Laboratório de Tecnologia Lítica do Museu de História Natural e Jardim Botânico da UFMG divulgaram nos últimos dez anos. Textos de periódicos científicos, anais de congressos, capítulos de livro, assim como dois resumos e um artigo

Journal of Lithic Studies (2017) vol. 4, nr. 3, p. 223-226

doi:10.2218/jls.v4i3.2534

Published by the School of History, Classics and Archaeology, University of Edinburgh ISSN: 2055-0472. URL: http://journals.ed.ac.uk/lithicstudies/

This work is licensed under a Creative Commons Attribution 2.5 UK: Scotland License. 
inédito foram revisados, alguns reduzidos, e estão reunidos nesse volume. No total, são doze textos, organizados, a nosso ver, de modo temático. Na ordem de apresentação: i. três teóricometodológico, que trazem as bases fundamentais da análise tecnológica de coleções líticas; ii. dois com resultados de trabalhos experimentais, voltados para identificação de estigmas técnicos; iii. quatro estudos de caso, abordando diferentes períodos e regiões do contexto arqueológico brasileiro; iv. um trazendo resultados experimentais de utilização de peças líticas; v. enfim, dois resumos de comunicações orais em congressos, que também abordam estudos de caso. A obra conta ainda com uma breve apresentação biográfica de cada autor, além da apresentação do próprio livro, ambas nas primeiras páginas. As referências bibliográficas foram todas agrupadas no final do livro.

O primeiro artigo, inédito, "Método para estudo de indústrias líticas lascadas: a análise tecnológica”, por J. Pelegrin, M.J. Rodet e D. Duarte-Talim, traz o procedimento prático para a realização de uma análise tecnológica: quais elementos observar, por que observá-los, como ordenar a análise, etc. Insiste ainda sobre a representatividade e o valor das coleções, questões prévias à análise que guiarão a problemática da pesquisa como também seu alcance interpretativo. O artigo relembra os conceitos de estado técnico e experiência do lascador, que embora não sejam o ponto principal de uma análise, devem sempre ser consideradas pelos pesquisadores. Um ponto importante que mereceria maior destaque pelos autores é que toda coleção lítica é única. Fichas, protocolos e formulários qualitativos ou quantitativos não devem ser simplesmente transferidos de uma coleção para outra Estes instrumentos de coleta de dados são elaborados de acordo com o contexto da coleção e os problemas de pesquisa.

$\mathrm{O}$ artigo seguinte, “As experimentações em tecnologia lítica”, de J. Pelegrin, originalmente publicado em espanhol, é fundamental, visto o interesse crescente dos estudantes pelos estudos de vestígios líticos e, em consequência, pela prática do lascamento. Embora a prática ajude bastante a compreender a relação matéria-prima $\times$ lascamento, o fato de treinar o lascamento não significa que se realize uma experimentação. Como esclarece o autor, a experimentação requer procedimentos rigorosos de preparação, desde a escolha da matéria-prima até a experiência do lascador, e de documentação. A necessidade de realizá-la deve sempre nascer de um problema arqueológico. A reprodução por si só, sem considerar métodos, técnicas e procedimentos empregados pelos grupos do passado, não passa de uma cópia morfológica e nos retroage aos primórdios dos estudos líticos.

“Uma terminologia para a indústria lítica brasileira”, por M.J. Rodet e M. Alonso, traz uma discussão ainda bem atual. Com exemplos concretos do mal entendido causado por uma terminologia pouco normatizada, os autores insistem na adoção de um vocabulário técnico e descritivo adequado, baseado em termos já consagrados na literatura brasileira, desde que sejam coerentes, e também na terminologia já consagrada internacionalmente, desde que adequada à realidade arqueológica brasileira. Um vocabulário comum é fundamental para o bom diálogo e compreensão entre os pesquisadores, mesmo que eles sigam linhas teóricas e metodológicas diferentes.

O quarto artigo "Princípios de reconhecimento de duas técnicas de debitagem: percussão direta dura e percussão direta macia (tendre) - experimentação com material do norte de Minas Gerais”, por M.J. Rodet e M. Alonso, elucida os estigmas diagnósticos destas duas técnicas de lascamento frequentemente encontradas nos contextos arqueológicos. Experimentam diferentes percutores em madeira, dando os primeiros indícios de sua aplicabilidade. Problematizar a percussão direta macia é tarefa laboriosa, pois percutores macios em cifre ou em madeira ainda não foram encontrados em contexto arqueológico brasileiro, deixando-nos numa busca às cegas diante da riqueza de nossos biomas. Os percutores duros, por sua vez, poderiam ter sido melhor explorados. Estes instrumentos são mais frequentes em contextos arqueológicos e mereciam uma descrição e exposição mais 
detalhada de suas características, matéria-prima, estigmas de utilização e eventualmente etapas do lascamento que teriam sido empregados.

Em seguida, o artigo "Experimentações da percussão sobre bigorna no cristal de quartzo”, por M.J. Rodet, D. Duarte-Talim e L. Fernandes, apresenta o mesmo propósito geral do artigo anterior, porém a falta de documentação visual adequada dos estigmas é a principal falha deste artigo. A importância das indústrias sobre quartzo, principalmente nos sítios de Minas Gerais, é bem conhecida. Neste sentido, os autores trazem boa contribuição ao descreverem detalhadamente um caso de figura, dentre as muitas possibilidades, quando se trata de quartzo e de percussão sobre bigorna. Com a avançar dos estudos arqueológicos e experimentais espera-se que as considerações sobre o modo de fratura, técnicas, métodos envolvidos e seus restos derivados serão melhor compreendidos e explicitados.

O sexto artigo, "Reflexões sobre as primeiras populações do Brasil Central: 'tradição Itaparica'”, de M.J. Rodet, D. Duarte-Talim, L.F. Bassi, discute a presumida homogeneidade de indústrias ditas da "tradição" Itaparica. Traçando um histórico, desde a primeira utilização do termo, e tentando sempre resgatar informações tecnológicas, percebe-se que concepções diferenciadas foram construídas em torno desse termo o que englobou indústrias tecnicamente bem diferentes: sobre seixos, peças bifaciais e, certamente, as conhecidas peças unifaciais de seção plano-convexa. Nessa perspectiva, indústrias datadas da transição PleistocenoHoloceno e Holoceno antigo devem ser melhor exploradas do ponto de vista tecnológico e contextual (tipo de sítio, disponibilidade de matéria-prima, etc.) antes de reduzidas a uma categoria pré-estabelecida. Os autores propõem uma reflexão que deveria ser adotada para qualquer período, região ou "tradição" arqueológica, nesse momento atual da disciplina, o qual revemos modelos do passado a partir de outras abordagens teórico-metodológicas.

Em seguida, "Análise tecnológica e cadeia operatória: uma nova proposta para a indústria lítica lascada das culturas ceramistas da Amazônia”, por M.J. Rodet, V. Guapindaia, A. Matos, é um artigo que trata da produção lítica das ocupações do Holoceno recente, uma linha de pesquisa cujos trabalhos se intensificam com os anos. Neste caso, as indústrias estão relacionadas às cerâmicas Pocó, mais antiga, e Konduri, mais recente, e possuem tendências distintas, a saber: fraturação de seixos sobre bigorna com matérias-primas selecionadas e produção de lascas por percussão direta dura utilizadas em seu estado bruto, respectivamente. Como se trata de um período pouco explorado do ponto de vista tecnológico, tanto lítico quanto cerâmico, o alcance dos resultados ainda se restringe à escala do sítio. Entretanto, a tendência é expandir e assim abordar questões sobre economia, trocas, mobilidade territorial, etc.

Focalizando no mesmo período do artigo anterior, "Uma cadeia operatória dentro de um sistema técnico: os (possíveis) dentes de ralador da Amazônia”, de D. Duarte-Talim, traz o estudo de instrumentos de cadeia operatória bem curta, os possíveis dentes de raladores, que comporiam os raladores, instrumentos de grande importância para o beneficiamento da mandioca. Sem o respaldo de análises traceológicas ou arqueobotânicas, a autora é consciente do limite de seu trabalho. Entretanto, ela busca uma boa alternativa para retirar mais informações destes objetos, ao consultar documentos e raladores etnográficos. Submetendo todas as fontes a um mesmo olhar tecnológico, foi possível aproximar os instrumentos arqueológicos aos dentes de raladores etnográficos.

O nono artigo, "Análise tecnomorfológica de transformações das lâminas de machado lascadas em sítios Aratu na Bahia”, de L. Fernandes, é um caso excepcional para se trabalhar o estado técnico dos instrumentos arqueológicos, no caso lâminas de machado lascadas. Após a produção, estes instrumentos foram utilizados, reavivados, quebrados, reestruturados e reconfigurados. Cada etapa pode ser religada ao instrumento inicial, mostrando toda sua evolução. Apesar de ter se focalizado nas lâminas de machado lascadas, o autor poderia ter detalhado esses outros instrumentos derivados, buscando classificá-los tecnologicamente. 
Teríamos, assim, uma ideia mais global da parafernália lítica desses grupos cerâmicos. Familiarizamo-nos com essa mesma coleção durante nosso mestrado e, desde então, preferimos chamar essas peças pelo termo geral de instrumentos bifacialmente lascados. Tal como peças do Neolítico europeu, os macrotraços de utilização que trazem no gume sugerem utilização no solo, e não para o abate de árvores. Até que estudos traceológicos e experimentais sejam mais conclusivos - os primeiros passos foram dados no artigo subsequente - preferimos manter este termo.

O último artigo, "Lâminas lascadas Aratu - traceologia e experimentação", por L. Fernandes, G. S. Nascimento e J.P. Silva, traz um trabalho experimental para identificação de macrotraços de utilização das lâminas de machado lascadas abordadas no artigo anterior. Os autores desenvolveram um programa experimental a partir de peças arqueológicas encontradas em sítios do Holoceno recente na Bahia e em Minas Gerais. As peças experimentais foram encabadas e empregadas no abate de árvores e na cava do solo. Os macrotraços de utilização - embotamento, brilho e estrias - são comparáveis aos arqueológicos e desenvolveram-se durante os trabalhos no solo, sendo pouco perceptíveis, ou ausentes, quando usados para abater árvores. As análises traceológicas, ainda incipientes, convergem para este resultado.

Por fim, os dois resumos "Abordagens tecnológicas do lascamento de cristal de quartzo: o estudo do sítio Bibocas II (Jequitaí - Minas Gerais, Brasil)”, por L.F. Bassi e M.J. Rodet e “As lâminas de machado lascadas do sítio lito-cerâmico Aratu de Piragiba, Bahia”, por M.J. Rodet, L. Fernandes e D. Duarte assinalam, brevemente, os resultados de estudos de coleção arqueológica feitos nos referidos sítios.

Além de explicitar as bases teóricas, experimentais e práticas da análise tecnológica, o livro retraça indiretamente o percurso da equipe do Laboratório de Tecnologia Lítica do MHNJB-UFMG. Atuando antes exclusivamente em Minas Gerais, através de parcerias, a equipe expandiu seu campo de estudo e estabeleceu trocas científicas riquíssimas que possibilitaram não somente um conhecimento mais aprofundado de outros contextos, como uma reflexão metodológica estimulante para adaptar-se a cada nova equipe e a cada novo contexto. Nesta evolução, o livro cumpre seu objetivo, anunciado na apresentação: "mostrar alterações no panorama em questão [estudos de coleções líticas], fruto da atuação de diversos grupos de pesquisa e da ampliação de cursos".

Todavia, alguns aspectos negativos devem ser levantados. A ausência de um revisor é notória: muitos erros gramaticais passaram desapercebidos aos olhos dos autores e organizadores da coletânea. Os erros tipográficos também foram comuns. Por fim, as ilustrações, tão importantes em publicações de tecnológica lítica, deveriam ter não somente uma qualidade de impressão melhor, mas também melhor seleção e apresentação, seguindo inclusive a normatização preconizada pela Escola Francesa. No geral, a apresentação material do livro deveria ter sido mais cuidadosa. Mas as falhas não diminuem a qualidade do conteúdo do texto e dos estudos apresentados.

Tecnologia lítica na Arqueologia Brasileira é um livro interessante para estudantes que se iniciam em arqueologia. Ao conduzir o leitor desde os fundamentos teóricos e práticos de estudo de uma coleção lítica, na perspectiva tecnológica, até os resultados concretos de tendência de indústrias, economia, evolução técnica de objetos obtidos em cada estudo de caso, tem-se a linha completa de desenvolvimento do pensamento científico. É indicado também para pesquisadores que encontrarão, num só volume, textos importantes, anteriormente espalhados pelos mais diversos suportes, alguns de difícil acesso. 